Kansas State University Libraries

New Prairie Press

\title{
DETERMINATION OF THE INOCULATION FREQUENCY, TIMING OF INOCULATION AND DOSE OF A BACTERIAL RUMINAL INOCULANT FOR ACIDOSIS PREVENTION IN FEEDLOT CATTLE
}

\author{
J. F. Boucher \\ W. J. Smolenski \\ J. A. Robinson
}

Follow this and additional works at: https://newprairiepress.org/agstatconference

Part of the Agriculture Commons, and the Applied Statistics Commons

\section{(c) (i) $(9)$}

This work is licensed under a Creative Commons Attribution-Noncommercial-No Derivative Works 4.0 License.

\section{Recommended Citation}

Boucher, J. F.; Smolenski, W. J.; and Robinson, J. A. (1994). "DETERMINATION OF THE INOCULATION FREQUENCY, TIMING OF INOCULATION AND DOSE OF A BACTERIAL RUMINAL INOCULANT FOR ACIDOSIS PREVENTION IN FEEDLOT CATTLE," Conference on Applied Statistics in Agriculture. https://doi.org/10.4148/2475-7772.1358

This is brought to you for free and open access by the Conferences at New Prairie Press. It has been accepted for inclusion in Conference on Applied Statistics in Agriculture by an authorized administrator of New Prairie Press. For more information, please contact cads@k-state.edu. 


\title{
DETERMINATION OF THE INOCULATION FREQUENCY, TIMING OF INOCULATION AND DOSE OF A BACTERIAL RUMINAL INOCULANT FOR ACIDOSIS PREVENTION IN FEEDLOT CATTLE
}

\author{
J.F. Boucher, W.J. Smolenski and J.A. Robinson \\ The Upjohn Company, 7000 Portage Rd., Kalamazoo, MI 49001
}

\begin{abstract}
We are evaluating the efficacy of a ruminal bacterial inoculant (Megasphaera elsdenii 407A) for prevention of acute acidosis in grain-fed cattle. As a part of this process, we examined the effects of inoculation frequency, timing of inoculation and dose of 407A for prevention of acute acidosis in ruminally fistulated cattle. Three levels of frequency, two levels of timing and three doses were considered, however, a complete $3 \times 2 \times 3$ factorial study was not run because of resource constraints. The study was conducted in two separate trials. The first was designed as a $3 \times 2$ factorial experiment with inoculation frequency and timing of inoculation while holding dose constant. The second trial was designed as a $2 \times 3$ factorial experiment involving inoculation frequency and 407A dose while holding timing constant. Both of these trials were conducted as complete block designs with seven blocks, with repeated measurements of ruminal lactic acid made across the duration of the two trials. Changes in ruminal $\mathrm{pH}$ for acutely acidotic cattle $(\mathrm{pH} \leq 5.0)$ are known to be driven largely by changes in total ruminal lactic acid concentration and that is why this variable was selected for these trials. Area under the lactic acid curves was selected as a method of summarizing across the repeated measures. Response surface techniques were used to determine the optimal settings for the treatment factors examined. Alternative designs will be contrasted.
\end{abstract}

Keywords: Megasphaera elsdenii 407A, 407A, Acidosis, optimal design, likelihood ratio test, response surface

\section{Introduction}

\section{a. Feedlot Industry}

The goal of the feedlot is to keep cattle healthy enough to consume feed and to convert that feed with maximal efficiency into muscle and fat so they can be sold at the predetermined weight (Jefferson Davis Assoc. 1991). Current feedlot practices involve obtaining cattle from various sources and growing the animals to a predetermined weight ( $\sim 1060 \mathrm{lbs}$ for heifers $\sim 1200 \mathrm{lbs}$ for steers). Cattle enter the feedlot at around 1 year old, however the age varies considerably, and they can weigh from 400 to 800 pounds. The cattle are segregated by sex and managed, maintained and marketed in pens of 100 to 300 animals. It generally takes about 140-150 days for a pen to reach market weight and at that point the packers bid on the pen and if 
successful the entire pen is delivered to the packers.

Cattle coming from the pasture to the feedlot are presented with a number of health related challenges. The process of shipping the cattle by truck or rail, exposure to large numbers of cattle and, therefore, other diseases, plus dietary changes upon entering the feedlot can all pose health risks to the incoming cattle. Most cattle enter the feedlot from the pasture and, therefore, their diet contains almost exclusively forage or roughage. The feedlots, however, want to switch the cattle from forage to grain (e.g. corn), since it is believed that a high percent grain diet allows cattle to gain weight and convert feed more efficiently than a forage diet. Forage grasses typically consumed by cattle contain about $80 \%$ cellulose and, unlike the human digestive system, the bacteria and protozoans in the rumen of cattle can break down the cellulose through the process of fermentation. This process forms products such as carbon dioxide and methane which are excreted and volatile fatty acids (VFAs) (e.g. acetate, propionate and butyrate) which are absorbed and oxidized (Hungate 1966).

Grain, on the other hand, can be readily broken down, digested and absorbed while also creating the necessary VFAs. Since grains are more easily digested, they are more easily converted into muscle and fat. There are, however, drawbacks to grain diets, the rumen has been adapted to forage for most of the life of the animal and introducing a high grain diet too quickly can result in acute indigestion also known as lactic acidosis. In many cases there is a sudden surge of the bacteria Streptococcus bovis in the rumen which produces lactic acid. This decreases ruminal $\mathrm{pH}$ as low as 4.0 and the acidity can remain high for a week to 10 days (figure $1 \mathrm{~A}$ ). If the lactic acid reaches a high enough level $(90 \mathrm{mM}$, figure $1 \mathrm{~B})$ and the ruminal $\mathrm{pH}$ is low (5.0) acute lactic acidosis can occur. Acidosis can result in reduced or suspended feed intake, malabsorption of nutrients, founder, liver abscess, polioencephalo-malacia, clostridial infection or death.

To avoid acidosis the cattle coming into the feedlot are adapted gradually to a high grain diet (85-95\% grain). Over a period of about 21 days and though a series of increasing percent of grain (50\%-95\%) diets (between 3 and 6 steps) cattle are adapted to the high grain ration. This period of adaptation is management intensive, the feedlot manager wants his cattle right on the edge of acidosis, since this is the most efficient use of feed. But crossing the edge into acidosis can be financially ruinous. Cattle stop eating, the feed conversion is no longer optimal and veterinary costs go up. So, they push the cattle as hard as they can in order to achieve the maximum gain in the shortest amount of time. It is expected that a group of cattle are considered to be performing well if there is a small incidence $(<1 \%)$ of acidosis (Jefferson Davis Assoc. 1991). Therefore, acidosis is a management related disease, if mistakes are made in the management of the dietary changes then acidosis can occur.

\section{b. Megasphaera elsdenii 407A}

To combat acute acidosis, the rumen contains bacteria that consume lactic acid, 
however, these bacteria take time (2-3 days) to reach the numbers needed to consume the lactic acid. One such lactic acid consuming bacterium Megasphaera elsdenii 407A (407A) has been isolated and can be grown outside the animal. 407A is a large gramnegative coccus, produces VFAs (acetate, propionate, butyrate and valerate) during growth on lactate and will grow at $\mathrm{pH}$ levels of $<5.0$. This bacterium, then, can be added to the rumen in cases of acidosis or before the onset of acidosis to consume the lactic acid and thereby prevent acute acidosis. The utility of such a bacterium lies not so much in reducing the frequency of acute acidosis below already acceptable levels, but rather with shortening the length of the grain adaptation period, reducing the number of diets fed and, hence the total quantity of forage fed to feedlot cattle.

\section{c. Objectives}

Bacterium 407A is being evaluated for prevention of acute acidosis. This study was designed to study the effects of inoculation frequency, timing of inoculation and dose of 407A for prevention of acute acidosis in ruminally fistulated cattle. This study was designed to determine the optimal treatment regimen. Hence, three specific objectives were considered: determine the number inoculations required (frequency), determine when the inoculation should start (timing) and determine the amount of 407A to be given (dose) to prevent acidosis.

\section{Experimental Design}

The animals used for this study were Angus and Angus $\times$ Hereford steers ranging in weight from 260 to $350 \mathrm{~kg}$, approximately. All cattle involved in this study were ruminally fistulated, a surgical procedure designed to create a passage from the surface of the skin to the rumen, to allow for easy access to the rumen. All cattle were allowed at least a 3 week recovery period from the surgery. For this study cattle were adapted to a high grain diet by switching from a forage diet to a $50 \%$ grain concentrate diet for 5 days (study days 1-5) then switching to a $90 \%$ grain concentrate diet for the remainder of the study (study day 6-20) (table 1). Such an abrupt diet switch has been reported to cause acute acidosis in untreated animals (Smolenski et al. 1990). The 407A treated groups were arranged in a $3 \times 2 \times 3$ factorial with frequency of inoculation (Freq) at levels $F_{1}, F_{2}$ or $F_{3}$ inoculations, timing of inoculation (Sday) which refers to the day that inoculations started at two different start days, $S_{1}$ and $S_{2}$ and dose of inoculation (Dose) of Low, Medium and High. The $3 \times 2 \times 3$ factorial with an untreated control gives a total of 19 treatment groups and the building used to house these cattle only allowed for 59 animals to be studied at one time. The cattle were housed in individual stalls within the building, however, 4 separate rooms were used, one room could accommodate 12 cattle, two rooms could hold 15 and the last room could house 17 cattle. It was believed necessary to consider room as a blocking factor. Although power calculations were not taken into account, it was decided that the 3 replicates this study would allow were not sufficient. It was, therefore, decided that the study would be run in two parts, sequential in time. 


\section{a. Possible Experimental Design}

It was necessary that room within the building be used as a blocking factor and the smallest room could hold 12 animals. So, if the scientist was willing to identify one level of one treatment factor that was of lesser importance than the other treatments then a $3 \times 2 \times 2$ factorial could be run in complete blocks and augmented with the treatment combinations involving the treatment level of lesser concern and the control group. For example, if the scientist were willing to identify the medium level of dose as not of primary concern then the design in table 2 could be used. Running the full factorial for 3 levels of Freq, 2 levels of Sday and 2 levels of Dose then augmenting this design with six blocks of the negative control and the remaining spaces with treatment combinations involving the medium level of dose in such a way that as many treatment comparisons involving the medium level of dose could be made (table 2).

If, on the other hand, the scientist was not willing to identify a treatment level of lesser concern then the full $3 \times 2 \times 3+1$ factorial could be considered if an alternative plan to assign treatments to blocks could be arranged. One simplistic way to assign treatments to blocks would be to assign the letters a-s to blocks in a cyclic manner with actual treatment combinations randomly assigned to the letters and then randomly assigned to stall within room (table 3). This design provides at least 6 replicates of each treatment.

The two possible designs presented can be evaluated by comparing their efficiency with a complete block design. The SAS/QC ${ }^{\circledR}$ procedure optex (SAS 1989) will determine the efficiency of an experimental design based on 3 criteria: the determinant of the information matrix (D-efficiency), the trace of the inverse of the information matrix (A-efficiency) and the maximum standard error for prediction (G-efficiency) (see appendix for $\mathrm{SAS}^{\circledR}$ code). Table 4 shows the efficiencies for these designs given above and for a complete block design with 19 treatments. Apart from determining the efficiencies of a design proc optex can determine an optimal design based on $\mathrm{D}$ - or A-optimality, however, the procedure does not allow for fixed and unequal block sizes, so an optimal design with the present constraints could not be obtained. From table 4 it can be seen that as compared to the complete block design the cyclic assignment shows little decrease in efficiency. The decrease in efficiency of the augmented $3 \times 2 \times 2$ is expected since little information is available on the treatment of lesser concern, but would have maximal efficiency for the $3 \times 2 \times 2$ factorial treatments.

\section{b. Actual Experimental Design}

Both of the experimental designs described and evaluated above were considered after the experiment had been completed and are presented as alternatives to the design that was actually used. The actual experimental design did not consider the $3 \times 2 \times 3+1$ factorial arrangement. Instead, the actual experiment was run in two parts, the first part would evaluate a $3 \times 2$ factorial arrangement of frequency of inoculation and 
timing of inoculation while holding the dose constant at the high level. For the second part of the study one of the treatments was Dose at 3 levels, and a second treatment was, determined after examining the results of the first part of the study, frequency of inoculation at two levels ( $\mathrm{F}_{1}$ or $\mathrm{F}_{2}$ inoculations) while holding the start of injections constant. Both parts 1 and 2 included an uninoculated control group (table 5).

The cattle were randomly assigned to either parts 1 or 2 of this study. Within each part the cattle were ranked and grouped by their average body weight taken on two consecutive days. They were grouped in groups of size seven, with the seven smallest steers in one group, the next smallest 7 in the next group and so on until a total of 7 groups were complete. The 7 groups were then randomly assigned to one the 4 rooms (3 rooms held 2 blocks) within the building, and, thus, the two factors of weight groups and room assignment made up the blocks. Parts 1 and 2 were both designed as randomized complete block designs with 7 blocks in each part and an individual steer as the experimental unit. The 7 steers within each block were randomly assigned to one of the seven treatments.

\section{Statistical Analyses}

Several response variables were measured in this study, but this paper will concentrate on the analyses pertaining to lactate for statistical illustrative purposes.

\section{a. Contribution to the Random Error}

\section{i. Lactate Measurements}

Three areas of the rumen were sampled (anterior, medial and posterior) for each lactate determination. The three samples were immediately frozen. For lactate determinations the samples were thawed, centrifuged and $1 \mathrm{ml}$ of supernatant from each sample were combined to form a pooled sample. The pooled samples were split and each split sample was analyzed through HPIC chromatography using two different chromatographs and the average of the two determinations was used as the amount of lactate $(\mathrm{mM})$. Lactate measurements were taken numerous times during the study period. Samples were collected 4 times on each of the first two days following the diet switch (study day 6 and 7). Samples were taken 2 times on days 8 and 9 and once on day 13 and 19 (table 1). Thus, a total of 14 repeated measures were taken on each animal.

\section{ii. Dose of $407 \mathrm{~A}$}

At the time of delivery the dose of $407 \mathrm{~A}$ can not be measured exactly, however, at later point in time it could be determined how much actual dose was delivered. Thus, the actual dose given can be compared to the target dose by calculating the percent of the target dose that was actually delivered: $100 *$ actual/target, mean $=92 \%$, standard 
deviation $=29 \%$ and range $=50-139 \%$. Thus, treatment differences found in this study are confounded with this variation in the doses.

The rumen sampling procedure and determination of lactate concentration and the variation in the dose of $407 \mathrm{~A}$ are not considered further and, therefore, contribute to the experimental error.

\section{b. Statistical Model}

Since part 2 of this study was designed after examining the results of part 1 , part 1 and part 2 were analyzed separately. A repeated measures analysis was considered as a method for analysis of these data, but for a number of reasons it was not appropriate. First, figure 2 displays the lactate treatment means over time, evident from the plot is a strong interaction between treatment and time, also from the figure it can be seen that there are many treatment by time means that are zero or close to zero. Second, fitting the repeated measures model to the lactate data and plotting the residual vs predicted (figure $3 \mathrm{~A}$ ) displays the large number of zeros in the data and possible heterogeneity of variance. Finally, the residual vs time plot more clearly shows the heterogeneity of variance among times (figure 3B). Thus, rather than attempt a repeated measures analysis the repeated measures were summarized by taking the area under the lactate curve (AUC) (additionally the peak height and time to peak were also be considered, but are not analyzed here). The analysis of variance (AOV) model included terms for the intercept, block, treatment and error with block and error treated as random effects. The treatment term was partitioned into the factorial effects and further into polynomial main effects and interactions. A response surface was fit using the significant $(\alpha=0.15)$ effects from the AOV and the smallest AUC within the experimental region was determined as the optimal treatment levels.

\section{Results and Discussion}

Figure 4A-B displays dot plots for the AUC for parts 1 and 2. The dot plots indicate the obvious difference between the 407A groups when compared to the control group. The dot plots, also, indicate that the range among the values within each treatment group may be different among treatment groups, so the homogeneity of treatment variance was tested. To test the homogeneity of variance two models were fit using proc mixed (SAS 1992) the first used a common variance and the second, allowed for separate variances for each treatment group. Since the common variance model is a simplification of the unequal variance model, a likelihood ratio test (LRT) could be conducted. The LRT is determined by taking the difference between the $-2 \log$ likelihood (-2LL) for each model, the resulting test statistic is chi-square distributed with the degrees of freedom equal to the difference between the number of parameters in the two models. This LRT of homogeneity of variance has the advantage over more commonly used tests (Bartlett, Shukla, Hartley's Fmax) since it allows for unbalanced data and any type of design, although its performance has not been measured. 
For part 1 , the common variance model resulted in a $-2 \mathrm{LL}=373$ with 2 variance parameters and for the unequal variance model the $-2 \mathrm{LL}=356$ with 8 variance parameters. Thus, the test for homogeneity of variance for part 1 gives the LRT Chisquare $=17$ with 6 degrees of freedom which results in a p-value of 0.01 . For part 2, the likelihood ratio test for homogeneity of variance for AUC was highly significant $\left(\chi^{2}=31 \mathrm{df}=6, \mathrm{p}<0.01\right)$. So, both parts 1 and 2 the AUC fails to meet the assumption of homogeneous treatment variance. One could attempt to transform the data to control the variance, or, as was done here, the unequal variance model could be used to analyze this data.

The analysis of variance for part 1 (table 6) indicates that the treatment effect was highly significant $(\mathrm{p}<0.01)$. Partitioning the treatment effects into the factorial effects, the Freq effect is significant at $\mathrm{p}=0.10$ and the SDay at $\mathrm{p}=0.01$ and their interaction was significant at $p=0.03$. Since a response surface is of interest the terms to include in the model were determined by further partitioning of these effects into polynomial effects. The tests of the polynomial effects indicate that both linear $(p=0.06)$ and quadratic $(p=0.11)$ effects of Freq and the linear effect of Sday $(p=0.01)$ could be included in the response surface model, as well as, the linear by linear interaction $(\mathrm{p}=0.01)$. The resulting model:

$$
\text { AUC }=B_{0}+B_{1} *(\text { Freq })+B_{2} *(\text { Freq })^{2}+B_{3}^{*}(\text { Sday })+B_{4} *(\text { Freq } * \text { Sday })
$$

The minimum AUC from the response surface within the experimental region occurs very close to Freq $=\mathrm{F}_{2}$ and $\mathrm{Sday}=\mathrm{S}_{2}$ (figure 5).

From part 1 it was clear that $F r e q=F_{2}$ and $S d a y=S_{2}$ was sufficient to prevent acidosis when compared to control, but it is unclear whether there was truly a difference between the $F_{2}$ and $F_{1}$ levels of Freq. Also, in part 1 the Dose was held constant at the High level, so for part 2 the 3 levels of Dose were tested and two levels of frequency $\left(F_{1}\right.$ and $\left.F_{2}\right)$ were included in the design.

The analysis of variance for part 2 (table 6) indicates that the treatment effect was highly significant $(\mathrm{p}<0.01)$. Partitioning the treatment into factorial effect indicates that the Dose effect was found to be not significant $(\mathrm{p}=0.97)$, the Freq effect was not significant $(\mathrm{p}=0.63)$ and the interaction of Dose and Freq was, also, not significant $(\mathrm{p}=0.51)$.

In conclusion, the treated groups provide good protection against lactic acidosis as compared to the control group and measured by lactate production. There was, however, insufficient evidence to indicate a Dose trend and there was insufficient evidence to indicate that $\mathrm{F}_{2}$ inoculations provide more protection against acidosis than $\mathrm{F}_{1}$. Hence, from the two parts of this study the following treatment regime is recommended: Dose $=$ Low, Freq $=F_{1}$ and $S d a y=S_{2}$. 


\section{Acknowledgements}

The authors would like to acknowledge the following individuals for there assistance with this study: R.C. Greening, S.F. Kotarski, K.K. Thurn, K. Barsuhn, R.L. Bell, D. Beauchamp, M. Kievit, K.J. Dame, B. Hibbard, K.D. Baker, D. Reeves and D.A. Wargolet

\section{References}

Hungate, R.E. 1966. The rumen and its microbes. Academic Press, New York, NY. Lactic acidosis in the feedlot: Reactions to a proposed new product. 1991. A report prepared for The Upjohn Company by Jefferson Davis Associates, Inc.

SAS Institute Inc. 1992. SAS ${ }^{\circledR}$ technical report p-229, SAS/STAT ${ }^{\circledR}$ software: changes and enhancements, release 6.07, Cary NC: SAS Institute Inc.

SAS Institute Inc. 1989. SAS/QC ${ }^{\circledR}$ software: Reference, Version 6, First Edition, Cary NC: SAS Institute Inc.

Smolenski, W.J., J.A. Robinson, R.C. Greening, M.L. Ogilvie, R.L. Bell, S.L. Fish and K. Barsuhn. 1990. Development of a model for the direct switch of cattle from a 50\% concentrate diet to induce symptoms of lactic acidosis with a consequent reduction in feed intake. The Upjohn Company Protocol \#607-7922-I-WJS-90-001. 


\section{Appendix}

The SAS code is given below to demonstrate how the data step and proc optex are used to determine the optimality criteria for a design.

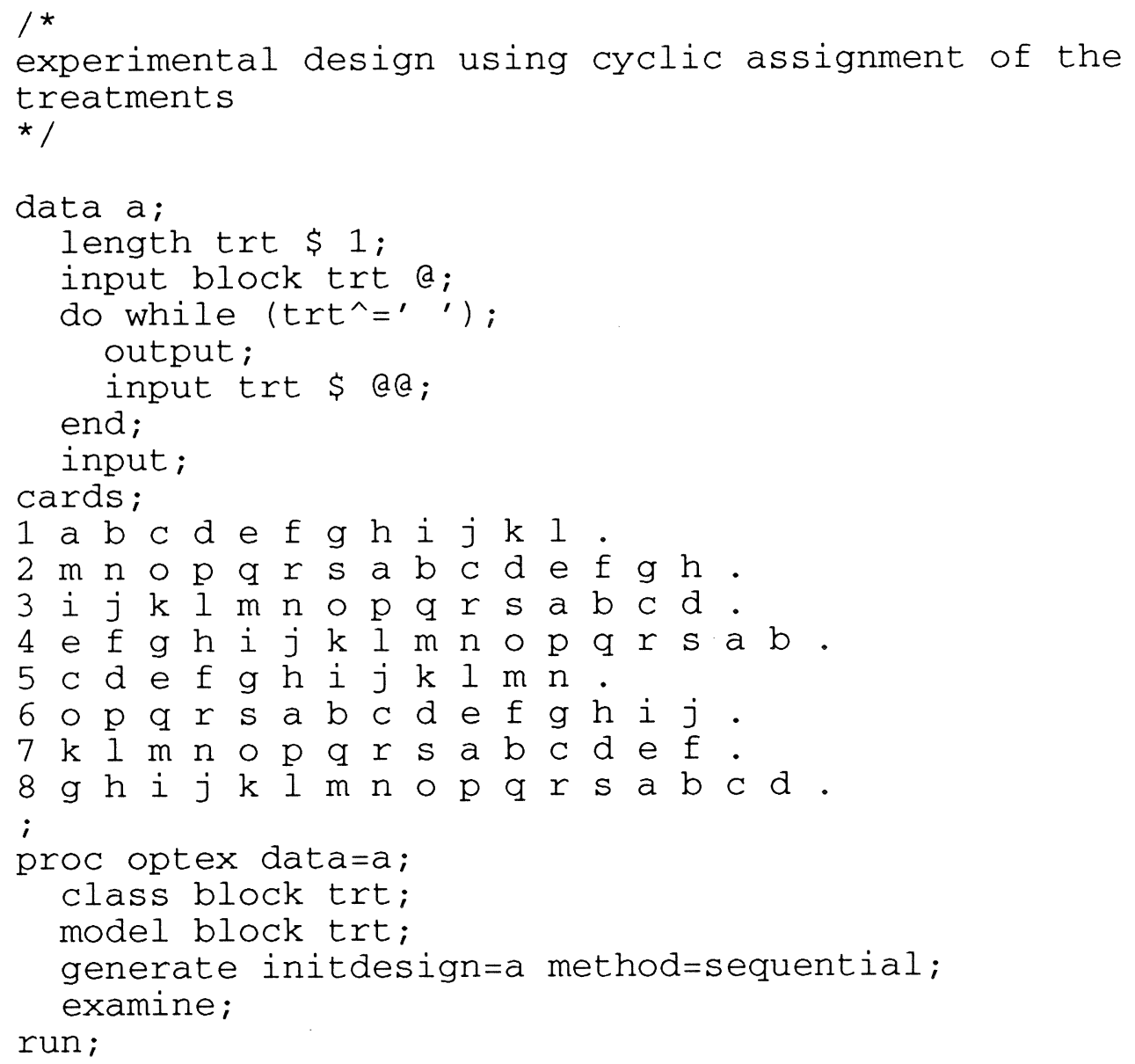


Table 1. Time line and study activities

\begin{tabular}{c|c|l}
\hline Study Day & Hour & Activity \\
\hline-30 to 0 & & Hay diet \\
1 & 0 & Switch to $50 \%$ grain concentrate diet \\
6 & 0 & Switch to $90 \%$ grain concentrate diet \\
6 & $0,6,12,16$ & Lactate samples \\
7 & $0,6,12,16$ & Lactate samples \\
8 & 0,12 & Lactate samples \\
9 & 0,12 & Lactate samples \\
13 & 6 & Lactate samples \\
19 & 6 & Lactate samples \\
\hline \hline
\end{tabular}

Table 2. Possible experimental design augmented $3 \times 2 \times 2$

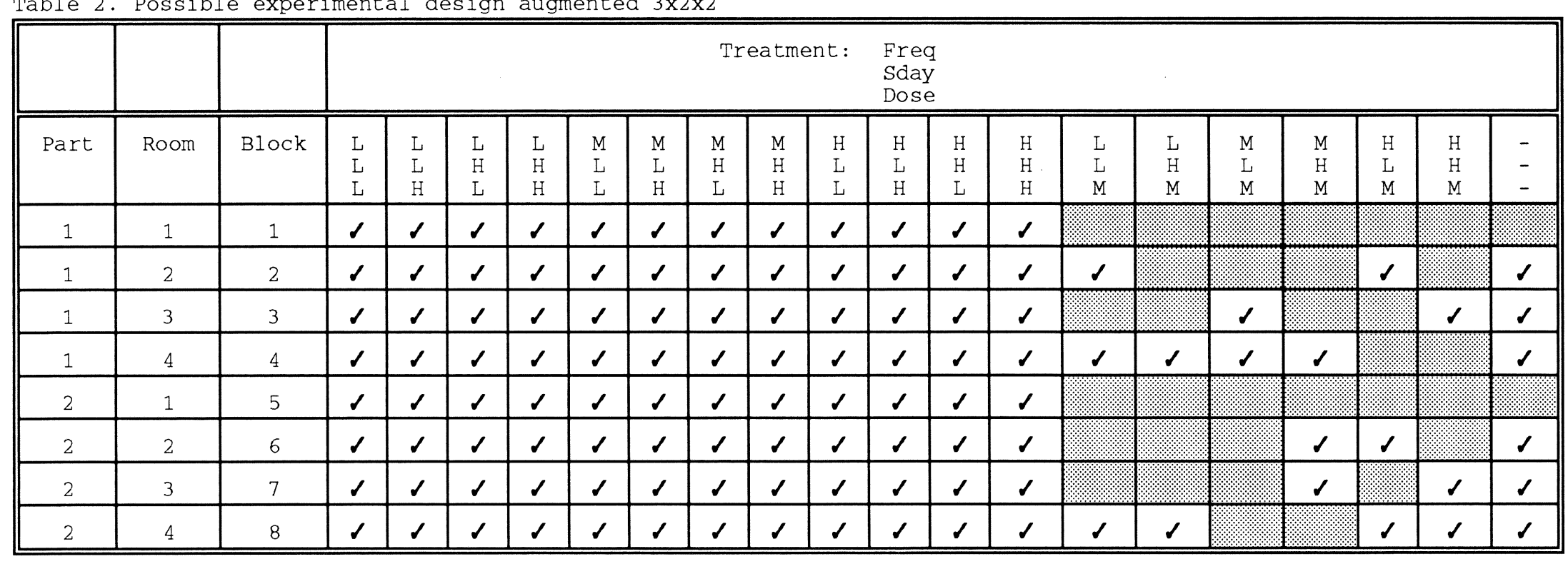


Table 3. Possible experimental design cyclic assignment (treatment randomly assigned to letter)

\begin{tabular}{|c|c|c|c|c|c|c|c|c|c|c|c|c|c|c|c|c|c|c|c|c|c|}
\hline \multirow[b]{2}{*}{ Part } & \multirow[b]{2}{*}{ Room } & \multirow[b]{2}{*}{$\mathrm{Block}$} & \multicolumn{19}{|c|}{ Treatment } \\
\hline & & & $\mathrm{a}$ & $\mathrm{b}$ & $\mathrm{C}$ & d & $\mathrm{e}$ & $\mathrm{f}$ & $\mathrm{g}$ & $\mathrm{h}$ & i & j & $\mathrm{k}$ & 1 & $\mathrm{~m}$ & $\mathrm{n}$ & o & $\mathrm{p}$ & $\mathrm{q}$ & $r$ & $\mathrm{~s}$ \\
\hline 1 & 1 & 1 & 1 & $\checkmark$ & $d$ & $\checkmark$ & $\checkmark$ & 1 & $\checkmark$ & 1 & $d$ & 1 & $\checkmark$ & 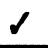 & & & & & & & \\
\hline 1 & 2 & 2 & 1 & 1 & 1 & 1 & 1 & 1 & 1 & 1 & & & & & 1 & $\checkmark$ & 1 & $\checkmark$ & 1 & 1 & 1 \\
\hline 1 & 3 & 3 & $\checkmark$ & $d$ & 1 & $\checkmark$ & & & & & $\checkmark$ & 1 & $\checkmark$ & $\checkmark$ & 1 & $\checkmark$ & $\checkmark$ & 1 & 1 & 1 & 1 \\
\hline 1 & 4 & 4 & $\checkmark$ & $\checkmark$ & & & 1 & 1 & 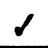 & $\checkmark$ & $d$ & $\checkmark$ & $d$ & $\checkmark$ & $\checkmark$ & 1 & $\checkmark$ & $\checkmark$ & $\checkmark$ & $\checkmark$ & $\checkmark$ \\
\hline 2 & 1 & 5 & & & 1 & 1 & 9 & 1 & 9 & 1 & 1 & 1 & 1 & 1 & 1 & 1 & & & & & \\
\hline 2 & 2 & 6 & 1 & 1 & 1 & 1 & 1 & 1 & 2 & 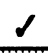 & 1 & 1 & & & & & 1 & 1 & 1 & 1 & 1 \\
\hline 2 & 3 & 7 & $\checkmark$ & 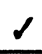 & 1 & 1 & 1 & 1 & & & & & 1 & $\checkmark$ & 1 & 1 & 1 & 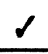 & 1 & 1 & 1 \\
\hline 2 & 4 & 8 & $\checkmark$ & $\checkmark$ & 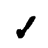 & $\alpha$ & & & $\checkmark$ & $d$ & $\checkmark$ & $\checkmark$ & $\checkmark$ & $\checkmark$ & $\checkmark$ & $\checkmark$ & $d$ & 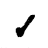 & $\checkmark$ & $\checkmark$ & $\checkmark$ \\
\hline
\end{tabular}

Table 4. Comparison of the efficiency of designs (SAS/QC Proc Optex)

\begin{tabular}{ccccc}
\hline Design & D eff & A eff & G eff & $\begin{array}{c}\text { Ave Std } \\
\text { Error }\end{array}$ \\
\hline Complete Block & 9.03 & 6.95 & 100 & 0.414 \\
Augmented $3 \times 2 \times 2$ & 8.20 & 5.26 & 60 & 0.528 \\
Cyclic assignment & 8.89 & 6.76 & 96 & 0.469 \\
\hline \hline
\end{tabular}


Table 5. Actual experimental design, 2 randomized complete block designs

\begin{tabular}{|c|c|c|c|c|c|c|c|c|c|c|c|c|c|c|c|c|c|c|c|c|c|}
\hline \multirow[b]{2}{*}{ Part } & \multirow[b]{2}{*}{ Room } & \multirow[b]{2}{*}{ Block } & \multicolumn{9}{|c|}{ Treatment: } & \multicolumn{10}{|c|}{$\begin{array}{l}\text { Freq } \\
\text { Sday } \\
\text { Dose }\end{array}$} \\
\hline & & & $\begin{array}{l}\mathrm{L} \\
\mathrm{L} \\
\mathrm{L}\end{array}$ & $\begin{array}{l}\mathrm{L} \\
\mathrm{L} \\
\mathrm{M} \\
\end{array}$ & $\begin{array}{l}\mathrm{L} \\
\mathrm{L} \\
\mathrm{H} \\
\end{array}$ & $\begin{array}{l}\mathrm{L} \\
\mathrm{H} \\
\mathrm{L}\end{array}$ & $\begin{array}{l}\mathrm{L} \\
\mathrm{H} \\
\mathrm{M} \\
\end{array}$ & $\begin{array}{l}\mathrm{L} \\
\mathrm{H} \\
\mathrm{H} \\
\end{array}$ & $\begin{array}{l}\text { M } \\
\text { L } \\
\text { L }\end{array}$ & $\begin{array}{l}\mathrm{M} \\
\mathrm{L} \\
\mathrm{M} \\
\end{array}$ & $\begin{array}{l}\mathrm{M} \\
\mathrm{L} \\
\mathrm{H} \\
\end{array}$ & $\begin{array}{l}\mathrm{M} \\
\mathrm{H} \\
\mathrm{L}\end{array}$ & $\begin{array}{l}\mathrm{M} \\
\mathrm{H} \\
\mathrm{M} \\
\end{array}$ & $\begin{array}{l}\mathrm{M} \\
\mathrm{H} \\
\mathrm{H} \\
\end{array}$ & $\begin{array}{l}\mathrm{H} \\
\mathrm{L} \\
\mathrm{L} \\
\end{array}$ & $\begin{array}{l}\mathrm{H} \\
\mathrm{L} \\
\mathrm{M} \\
\end{array}$ & $\begin{array}{l}\mathrm{H} \\
\mathrm{L} \\
\mathrm{H} \\
\end{array}$ & $\begin{array}{l}\mathrm{H} \\
\mathrm{H} \\
\mathrm{L}\end{array}$ & $\begin{array}{l}\mathrm{H} \\
\mathrm{H} \\
\mathrm{M}\end{array}$ & $\begin{array}{l}\mathrm{H} \\
\mathrm{H} \\
\mathrm{H} \\
\end{array}$ & $\begin{array}{l}- \\
- \\
\end{array}$ \\
\hline 1 & 1 & 1 & & & $d$ & & & $d$ & & & $d$ & & & $\checkmark$ & & & 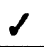 & & & $d$ & 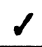 \\
\hline 1 & 2 & 2 & & & $a$ & & & 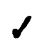 & & & $d$ & & & $d$ & & & $d$ & & & 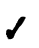 & $d$ \\
\hline 1 & 2 & 3 & & & 1 & & & 9 & & & 9 & & & 1 & & & 9 & & & 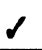 & $\checkmark$ \\
\hline 1 & 3 & 4 & & & 1 & & & 1 & & & 1 & & & $\checkmark$ & & & $\checkmark$ & & & $\checkmark$ & 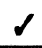 \\
\hline 1 & 3 & 5 & & & 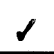 & & & 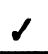 & & & 9 & & & 1 & & & $a$ & & & 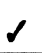 & 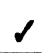 \\
\hline 1 & 4 & 6 & & & 8 & & & $\checkmark$ & & & $\checkmark$ & & & $d$ & & & $\alpha$ & & & $d$ & $s$ \\
\hline 1 & 4 & 7 & & & 8 & & & 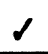 & & & 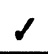 & & & $\checkmark$ & & & 9 & & & 9 & 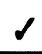 \\
\hline 2 & 1 & 1 & & & & $\alpha$ & $d$ & $d$ & & & & 1 & 1 & $d$ & & & & & & & 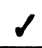 \\
\hline 2 & 2 & 2 & & & & 1 & 1 & 9 & & & & 1 & 1 & 1 & & & & & & & $s$ \\
\hline 2 & 2 & 3 & & & & 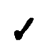 & $d$ & $\checkmark$ & & & & 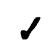 & $d$ & $d$ & & & & & & & 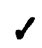 \\
\hline 2 & 3 & 4 & & & & 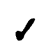 & $\checkmark$ & $\checkmark$ & & & & $\checkmark$ & $d$ & $\checkmark$ & & & & & & & $\checkmark$ \\
\hline 2 & 3 & 5 & & & & 1 & $d$ & 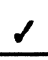 & & & & 1 & $d$ & 1 & & & & & & & 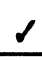 \\
\hline 2 & 4 & 6 & & & & 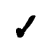 & $\checkmark$ & $\checkmark$ & & & & $d$ & $d$ & $\checkmark$ & & & & & & & $\checkmark$ \\
\hline 2 & 4 & 7 & & & & $\checkmark$ & $\checkmark$ & $\checkmark$ & & & & $\checkmark$ & $\alpha$ & $\checkmark$ & & & & & & & $\checkmark$ \\
\hline
\end{tabular}


Table 6. Parts 1 and 2 analysis of variance for lactate AUC (mM) allowing a different variance for each treatment

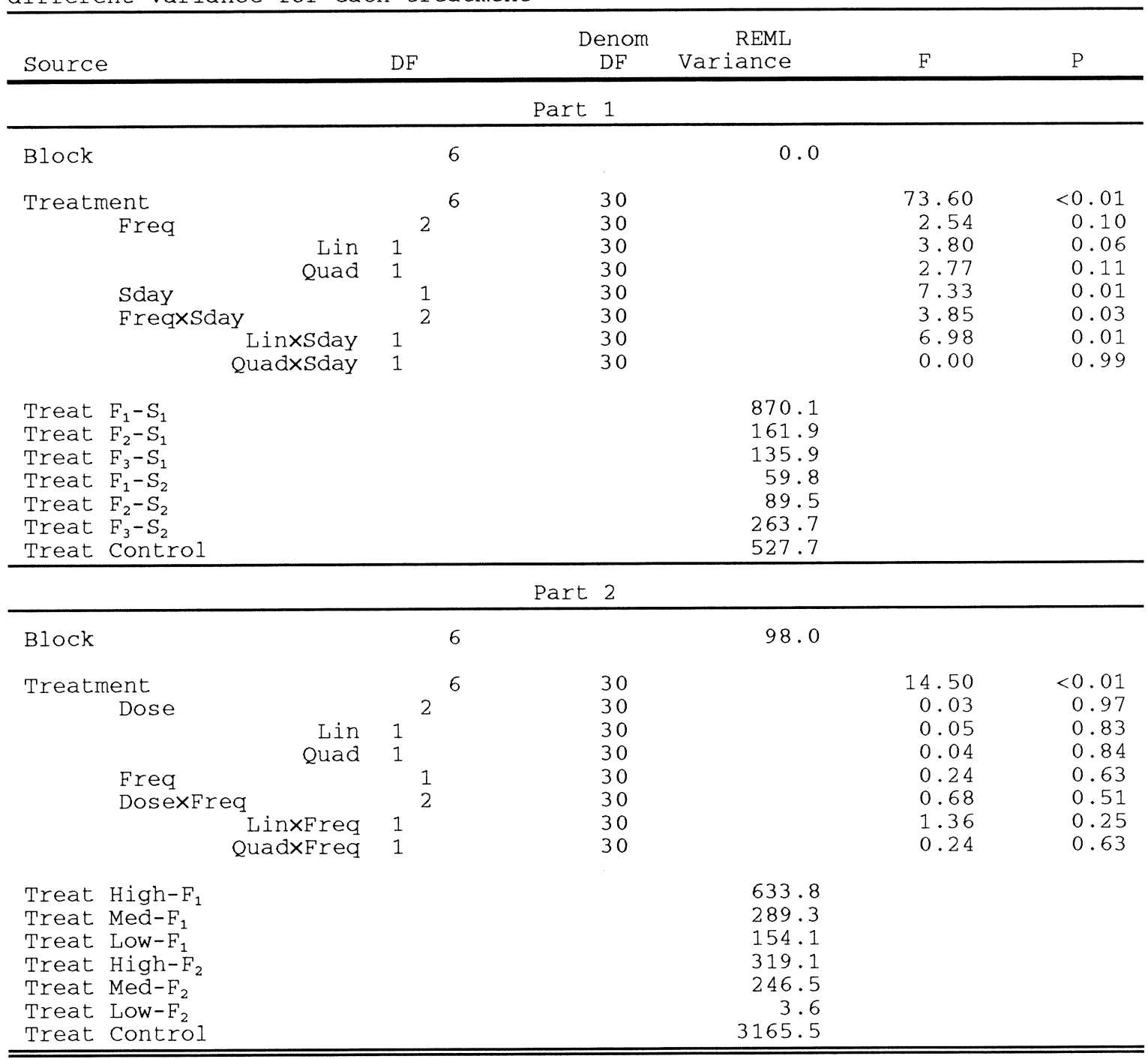



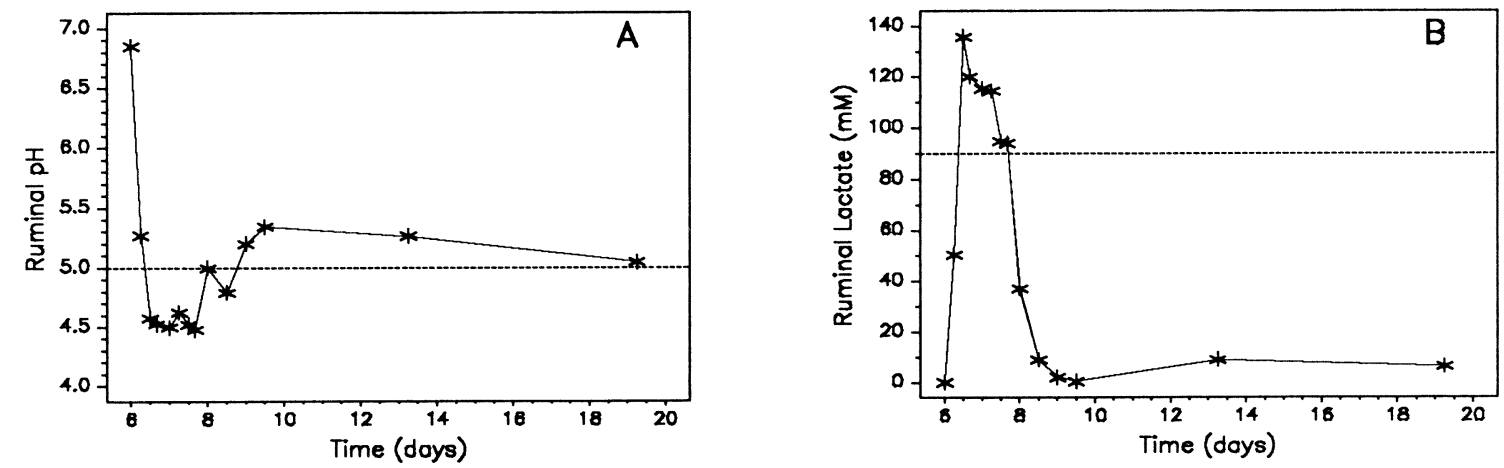

Figure 1. Ruminal $\mathrm{pH}$ (A) and ruminal lactate (mM) (B) means for untreated controls $(n=7)$ where day 6 was the switch from a 50/50 forage/grain diet to $10 / 90$ forage/grain diet.

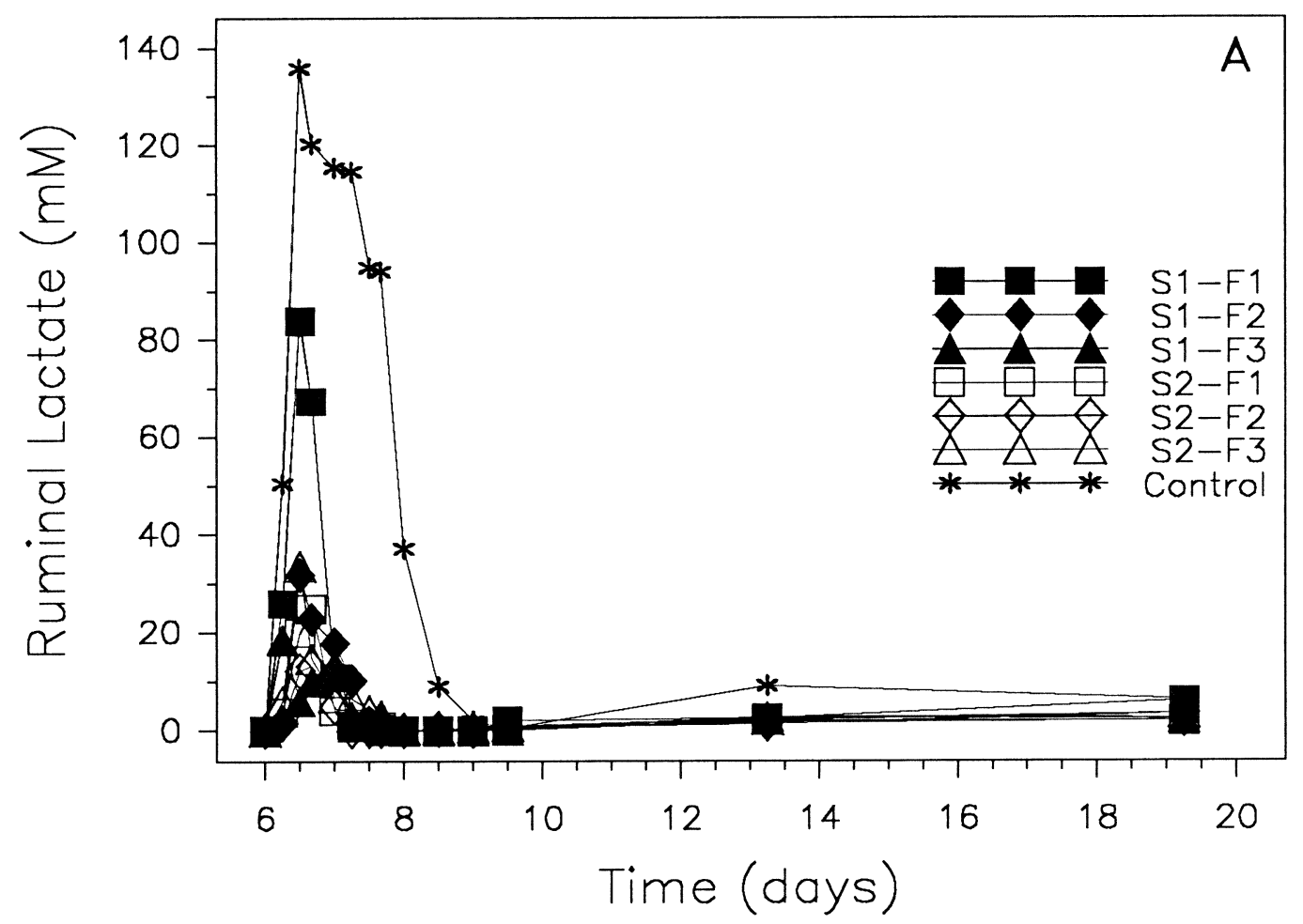

Figure 2. Part 1 treatment by time interaction means for lactate 

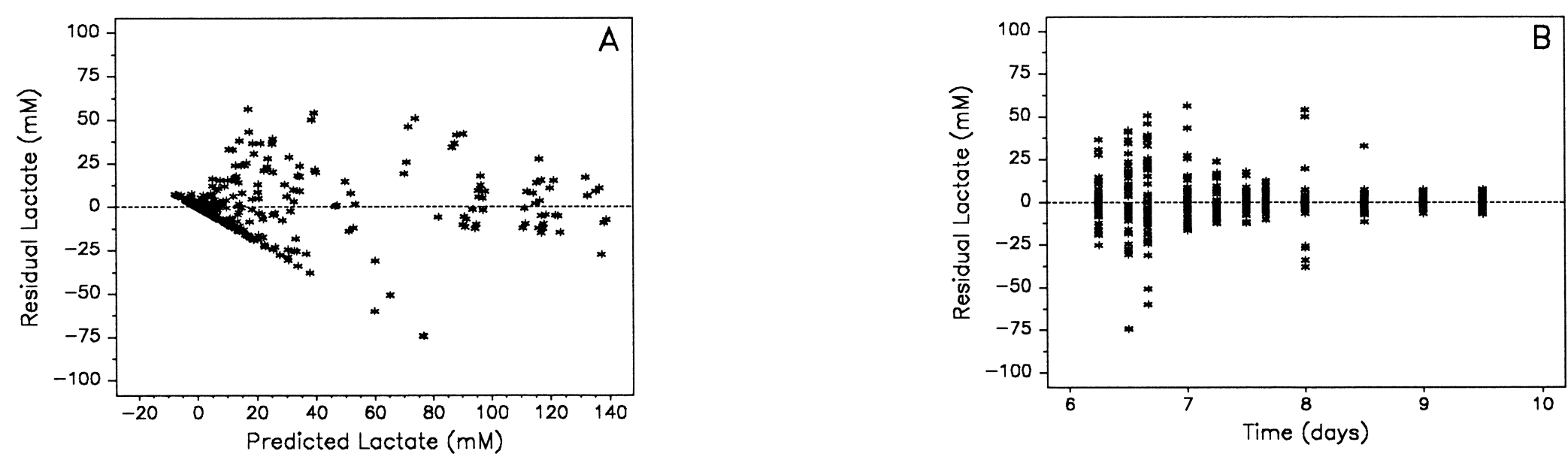

Figure 3. Part 1 residual versus predicted (A) and residual versus time (B) for the repeated measures model with $\Sigma=\sigma^{2} I$
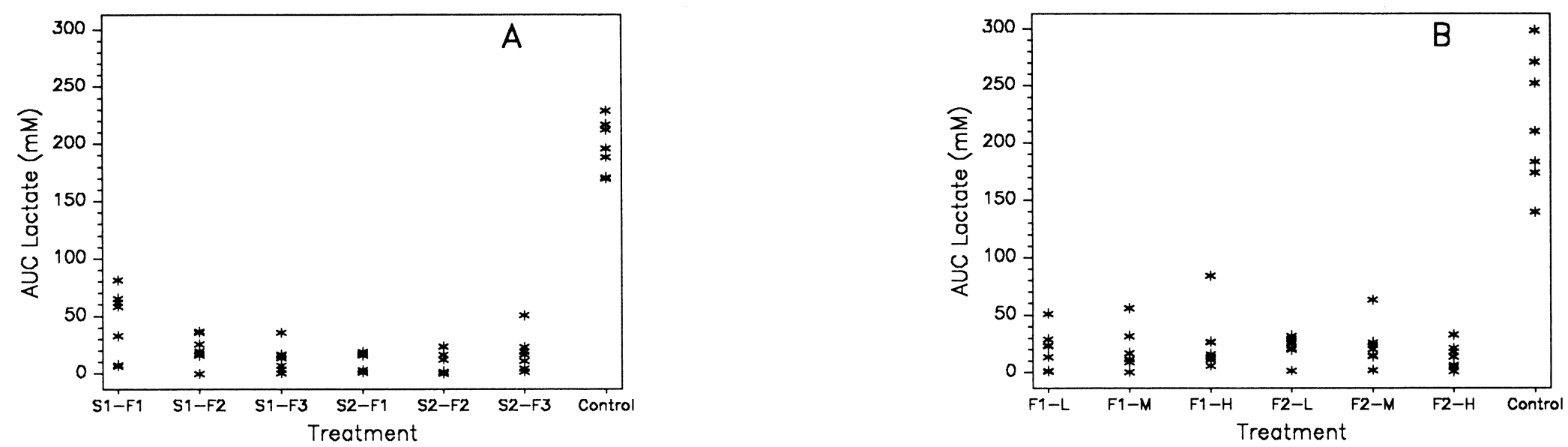

Figure 4. Dot plots area under the lactate curve for part 1 (A) and part 2 (B) 


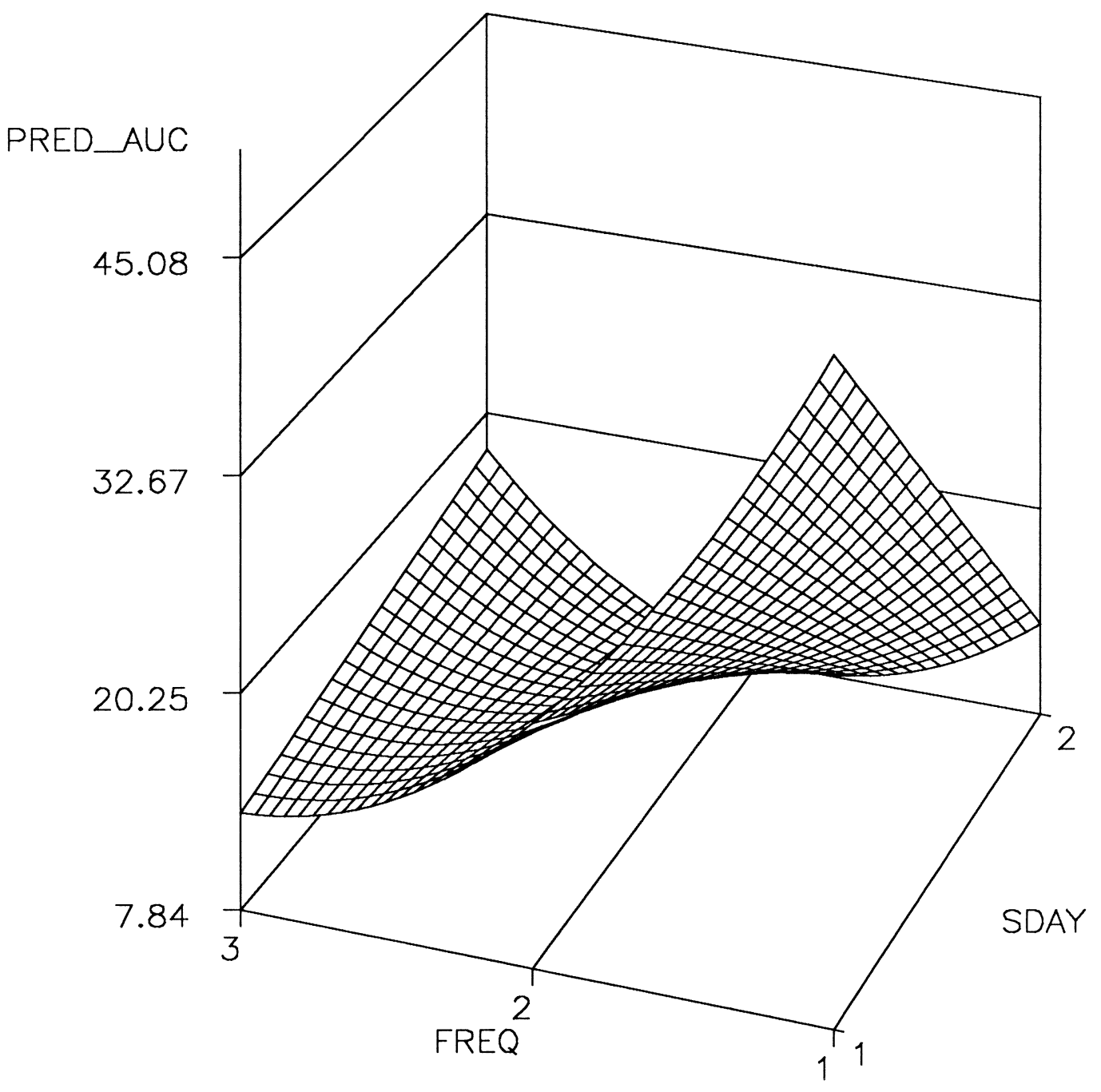

Figure 5. Response Surface for area under the lactate curve for part 1, 1ocal minimum at Freq $=F_{2}$ and Sday $=S_{2}$. 